\title{
Revisión bibliográfica de Implantología Bucofacial del año 2011. Segunda parte
}

Bibliographic review of Oral Implantology of year 2011. Second Part

\author{
SÁNCHEZ GARCÉS M Ma A* \\ GARCÍA DELANEY C** \\ MONTSERRAT BOSCH M** \\ DÍAZ CAMPOS E** \\ NOGUEIRA MAGALHÃES, $\mathbf{P} * *$ \\ HERRANZ APARICIO $\mathrm{J} * *$ \\ GAY ESCODA C***
}

Sánchez Garcés $M^{a} A$, García Delaney C, Montserrat Bosch M, Díaz Campos, E, Nogueira Magalhães P, Herranz Aparicio, J, Gay Escoda C. Revisión bibliográfica de Implantología Bucofacial del año 2011. Segunda parte. Av Periodon Implantol. 2013; 25, 2: 99-117.

\section{RESUMEN}

La gran diversidad de fuentes de información que nos proporciona la literatura científica junto al escaso tiempo de que disponen los profesionales de la Odontología para consultarlas, ha motivado a los autores a efectuar una revisión de la literatura científica publicada a lo largo del año 2011 en el campo de la Implantología Bucofacial. Con este fin se han agrupado los diferentes artículos indexados consultados en distintos apartados (elevación del seno maxilar, cirugía guiada y cirugía mínimamente invasiva, regeneración ósea guiada, implantes cigomáticos y factores de crecimiento), con el fin de facilitar una buena puesta al día.

PALABRAS CLAVE: Implantología bucal, elevación seno maxilar, regeneración ósea guiada, factores de crecimiento, cirugía guiada, implantes zigomáticos.

\section{SUMMARY}

The diversity existing in the scientific literature information sources and the lack of available time to consult them, have encouraged the authors of this paper to carry out a review of the scientific literature published in year 2011 regarding Oral Implantology. Thus, we classified the articles into different categories (sinus lift, guided surgery and minimally invasive surgery, guided bone regeneration, zygomatic implants and growing factors), then a more comprehensive updating can be made.

KEY WORDS: Oral implantology, sinus lift, guided bone regeneration, growth factors, guided surgery, zygomatic implants.

Fecha de recepción: 1 de abril de 2013.

Fecha de aceptación: 26 de abril de 2013.

* Doctora en Medicina. Estomatóloga. Máster en Cirugía e Implantología Bucal. Profesora asociada de Cirugía Bucal. Profesora del Máster de Cirugía Bucal e Implantología Bucofacial. Facultad de Odontología de la Universidad de Barcelona. Investigadora del Instituto IDIBELL.

** Licenciado en Odontología. Residente del Máster de Cirugía Bucal e Implantología Bucofacial. Facultad de Odontología de la Universidad de Barcelona.

*** Doctor en Medicina. Estomatólogo. Especialista en Cirugía Maxilofacial. Catedrático de Patología Quirúrgica Bucal y Maxilofacial. Director del Máster de Cirugía Bucal e Implantología Bucofacial. Facultad de Odontología de la Universidad de Barcelona. Investigador coordinador del Instituto IDIBELL. Jefe del Departamento de Cirugía Bucal, Implantología Bucofacial y Cirugía Maxilofacial del Centro Médico Teknon. Barcelona. 


\section{INTRODUCCIÓN}

Desde que surgió la aplicación de los implantes dentales de titanio en los años 50, la Implantología Bucofacial ha cobrado auge de forma que hoy en día el tratamiento restaurador con implantes constituye la primera opción terapéutica en la rehabilitación bucodental. Debido a su alta tasa de éxito y supervivencia, así como al lanzamiento de nuevos productos al mercado, su uso se ha visto incrementado año tras año en las últimas décadas. Gracias a los últimos avances en materiales y técnicas, hoy en día, a la gran mayoría de los pacientes que presentan algún tipo de déficit óseo, se les puede indicar una prótesis implantosoportada con un resultado predecible. Este artículo de revisión analiza algunas técnicas asociadas a la colocación de implantes que forman parte de estos avances.

\section{ELEVACIÓN DEL SENO MAXILAR}

La presencia del seno maxilar limita la altura ósea disponible para la instalación de implantes dentales en los sectores posteriores del maxilar superior. Esta restricción anatómica se acentúa tras la remodelación y pneumatización sinusal que se produce como consecuencia de la extracción de los molares y de los premolares superiores. Sin embargo, esta situación negativa no está totalmente exenta de ventajas, dado que el maxilar superior está compuesto especialmente por hueso esponjoso y el seno maxilar está recubierto por la membrana de Schneider, lo que crea una situación en la que se garantiza un gran aporte sanguíneo; que a su vez facilita la regeneración ósea en el espacio creado entre la membrana sinusal y el suelo óseo del seno maxilar (1).

\section{Técnicas}

En 1980, Boyne y James, usando la técnica de CaldwellLuc con un abordaje a través de la fosa canina fueron los primeros en describir la colocación de un injerto óseo autólogo entre la membrana sinusal y el suelo antral. Posteriormente, Tatum en 1986, publicó una modificación de la técnica clásica de Caldwell-Luc elevando la membrana de Schneider a través de la cara lateral del seno maxilar (2). Summers en 1994, describió una técnica con abordaje crestal usando osteótomos, con la ventaja de ser más conservadora, más rápida y que favorece más la regeneración ósea que la técnica de la ventana lateral. Sin embargo, es necesaria una altura ósea mínima para llevarla a cabo, ya que con esta técnica transalveolar se suele obtener solo un aumento de 3 a $4 \mathrm{~mm}$ de elevación. Por este motivo, cuando existen reabsorciones más severas será necesario indicar un abordaje sinusal lateral (1).

En un estudio de Uckan y cols. (3) se consiguió una ganancia media de altura ósea de $2,8 \mathrm{~mm}$ con la técnica transalveolar, frente a $4,7 \mathrm{~mm}$ con la técnica de abordaje lateral, aunque se han llegado a describir aumentos de hasta 10-12 $\mathrm{mm}$ a través de esta última vía de abordaje.

El hueso remanente es un factor decisivo para la elección de la vía de abordaje; por lo que se recomienda que, cuando el hueso es de buena calidad con una altura $\geq 5-6 \mathrm{~mm}$, el implante puede instalarse simultáneamente con o sin injerto óseo. Sin embargo, cuando el hueso remanente es de mala calidad y con $\leq 5 \mathrm{~mm}$ de altura, será necesaria una antrostomía lateral con regeneración ósea (4) teniendo en cuenta que, se precisa un mínimo de $5 \mathrm{~mm}$ de hueso alveolar si se pretende colocar los implantes en la misma fase quirúrgica. Aunque en un estudio en el que se valora la supervivencia de implantes colocados en un hueso remanente de 2-5 mm de altura, el porcentaje de éxito fue del $93,3 \%$ (5), siempre y cuando la estabilidad primaria fuera la adecuada (6).

Para Rosen y cols. citados por Bernadello y cols. (7) el porcentaje de supervivencia con la técnica transcrestal es del $96 \%$ cuando el hueso residual es $\geq 5 \mathrm{~mm}$, pero disminuye hasta un $85 \%$ cuando la altura ósea es $\leq 4$ $\mathrm{mm}$, aunque estos mismos autores, en un estudio en el que evaluaron los resultados de los implantes colocados en crestas óseas menores de $5 \mathrm{~mm}$, obtuvieron una supervivencia del $96,3 \%$ de los implantes.

El abordaje crestal o transalveolar se considera menos invasivo y cursa con un mejor postoperatorio, por lo tanto está aumentando el interés por su aplicación y la mejora de esta técnica. La técnica original fue diseñada para usar osteótomos de diversos diámetros, creando finalmente una fractura en tallo verde del suelo del seno maxilar al aplicar una fuerza manual en sentido vertical. Las complicaciones que suelen asociarse a esta técnica son el vértigo posicional paroxístico benigno debido a la percusión del osteótomo y la perforación de la membrana antral (8).

Hay disponibles dos tipos de osteótomos, los que necesitan la acción de un martillo para fracturar el suelo del seno (fuerzas percutivas), o los osteótomos roscantes que prescinden de esta acción (fuerzas vibratorias). 
Ambas situaciones, unidas a la hiperextensión de la cabeza del paciente durante la maniobra, puede dar lugar a un vértigo posicional paroxístico benigno debido al despegamiento de los otolitos que quedan flotando en la endolinfa. De los factores causales de esta complicación, las fuerzas de percusión han demostrado ser las responsables en mayor medida (9).

Otro de los inconvenientes del uso de osteótomos es la perforación de la membrana sinusal, para minimizar su incidencia se han introducido diversos métodos de elevación, como el uso de la presión hidráulica controlada cuyo sistema se explica por el principio de Pascal, así al ejercerse una misma presión en todos los puntos de la membrana; se reduce el estrés en un punto concreto (8). Incluso al comparar este sistema con el abordaje lateral mediante cirugía piezoeléctrica, se producen un $25 \%$ más de perforaciones con este último sistema (10). Siguiendo un mecanismo similar, también se ha reportado el uso de un balón que se hincha progresivamente expandiéndose por debajo de la membrana antral aplicando la misma fuerza en toda su superficie, según sus autores está especialmente indicada en los edentulismos unitarios (11).

La cirugía piezoeléctrica reduce la perforación de la membrana sinusal a un $7 \%$ comparada con el $30 \%$ que aparece con el uso de material rotatorio. Esto es debido a que la vibración ultrasónica corta sólo estructuras mineralizadas respetando los tejidos blandos, además hay una mayor precisión y favorece un mayor confort del paciente $(4,12)$. Con el mismo objetivo se pueden usar fresas especiales, como las descritas por Cosci, cuya forma previene la perforación de la membrana removiendo únicamente la cortical ósea $(7,13)$.

Pocos estudios analizan la colocación de implantes inmediatos postextracción en combinación con una elevación de seno maxilar. Se puede efectuar con el objetivo de disminuir el tiempo de tratamiento y se basa en practicar la técnica crestal con osteótomos tras la extracción de un molar o un premolar; con la colocación simultánea de un implante. En el caso de los premolares el implante se ancla en la cortical palatina y en los molares se aprovecha el septo interradicular para este fin. Sin embargo, se ha descrito una ganancia ósea muy variable (l a $8 \mathrm{~mm}$ ) (14-16).

También se han analizado diferentes métodos para abrir la ventana ósea sin lacerar la membrana sinusal en la técnica de abordaje lateral. Para ello, se han descrito varias opciones como el uso de material rotato- rio, trefinas, ultrasonidos y el láser (17). Según un estudio de Peñarrocha-Diago y cols. (18) las perforaciones de la membrana sinusal son más frecuentes con el material rotatorio $(7 \%)$ que con la técnica de ultrasonidos $(1,7 \%)$, asociándose a una supervivencia de los implantes y una ganancia ósea mayor en este último grupo.

En cuanto al tiempo de carga tras la colocación de implantes en la elevación sinusal con el abordaje lateral, se estima en 8-10 meses cuando se injerta un material heterólogo y de 6-8 meses cuando se mezcla con hueso autólogo en un porcentaje 1:1. En cambio, Jensen citado por Kim y cols. (6), considerando un periodo de cicatrización estándar de 4 meses, recomendó esperar 1,2 veces más en casos con hueso residual $<5 \mathrm{~mm}$ y 0,8 veces más para alturas óseas de $>9 \mathrm{~mm}$. Kim y cols. (6), revisan este apartado concluyendo que el pronóstico a corto plazo de los implantes colocados en crestas alveolares $\leq 3 \mathrm{~mm}$ es el mismo que rehabilitando protésicamente a los 4 y 6 meses, siempre y cuando la estabilidad primaria obtenida en la primera fase haya sido la adecuada.

Como último recurso, en casos de extrema reabsorción ósea o si se desea rehabilitar un plano oclusal que no puede ser corregido con ortodoncia, se puede realizar una osteotomía segmentaria. Hwang y cols. (19) añaden esta técnica a las indicaciones del uso de un sistema piezoeléctrico, con la finalidad de preservar la integridad de la membrana sinusal y la arteria alveolar superior posterior durante el transcurso de la osteotomía.

El "gold standard" de los materiales de injerto es el hueso autólogo cortical y esponjoso (intraoral, de calota craneal o de la cresta ilíaca) porque contiene células vivas y todos los factores responsables de la osteoinducción, osteoconducción y osteoformación. Pero también posee desventajas como la limitada disponibilidad de zonas donantes intraorales, la morbilidad causada en otras áreas y la rápida e impredecible reabsorción que pueden sufrir. Para evitar estas complicaciones se ha propuesto el uso de sustitutos óseos como son los xenoinjertos (procedencia animal), aloinjertos (procedencia humana) y materiales aloplásticos (sintéticos). Dentro de los autoinjertos el bloque óseo de mentón es el que muestra menos reabsorción, seguido del hueso particulado procedente de la cresta ilíaca y por último los bloques de cresta ilíaca (20). También pueden obtenerse partículas óseas de áreas intraorales mediante un rascador para evitar un segundo campo quirúrgico (21). 
Los xenoinjertos, gracias a sus características fisicoquímicas presentan una gran osteoconducción. Los de uso más común son los de origen bovino y porcino, sin embargo, el hueso equino también se ha ensayado obteniendo resultados alentadores (22). El hueso bovino mineralizado y desproteinizado ha sido el material más estudiado dando como resultado menores reabsorciones a largo plazo que los injertos autólogos, independientemente del tamaño de las partículas $(23,24)$.

Los aloinjertos han sido utilizados clínicamente desde que se introdujeron en 1889 en diferentes formas, una de ellas es como una matriz ósea desmineralizada. Actualmente proceden de bancos de tejidos que se encargan de su obtención, deshidratación y esterilización (25). La forma desmineralizada, contiene proteínas morfogenéticas que estimulan la osteoinducción, sin embargo al reabsorberse con rapidez se suelen mezclar con otros materiales alogénicos o sintéticos (hialuronato sódico, sulfato cálcico, lecitina, colágeno porcino o glicerol) para proveer una estructura sobre la cual las células endoteliales migren y proliferen con la finalidad de mejorar la angiogénesis y la osteoconducción (26).

En cuanto a los materiales sintéticos, la hidroxiapatita sintética en matriz de colágeno o de alga marina natural (con o sin mezclar con hueso autólogo) ofrecen buenos resultados $(13,27,28)$, al igual que su mezcla con ß-sulfato tricálcico (29).

Existen varios artículos que comparan diferentes tipos de materiales en búsqueda del más óptimo. Sin embargo, también se plantea la posibilidad de prescindir del injerto de relleno, aunque la mayoría de autores opinan que es más probable una ganancia ósea en las zonas regeneradas con materiales $(13,30)$, especialmente cuando se usa un xenoinjerto (31). Cuando se prescinde de los materiales, el coágulo sanguíneo actúa como tal, es decir que es un excelente portador de factores de crecimiento que facilitan la proliferación celular desde la pared ósea y por debajo de la membrana sinusal. Su parte central está ocupada por hematíes, en contraste con los injertos cuyo espacio central está completamente invadido por células mesenquimales. Cuando no se usa material de regeneración, la parte apical del implante cuando se efectúa una elevación de seno maxilar con colocación simultánea de implantes, puede quedar en contacto con el tejido conectivo sinusal y, por lo tanto, no oseointegrarse. Según algunos autores, este inconveniente puede salvarse con el uso de plasma rico en plaquetas y con fibrinógeno $(16,32)$.
Con el objetivo de acortar los tiempos de cicatrización se han estudiado potentes materiales osteoinductores como la superfamilia de los factores de crecimiento $B$ (proteínas morfogenéticas recombinantes, factores de crecimiento y diferenciación) sin demostrarse una formación más rápida de hueso en los grupos a los que se les aplicaban estas sustancias (33-35).

En la "The Sinus Graft Consensus Conference" de 1996, el material alogénico obtuvo el menor porcentaje de supervivencia de los implantes con un $85 \%$, seguido del autoinjerto con un $88,7 \%$ y de los materiales sintéticos con un $97,5 \%$. Al mezclar un material sintético con hueso autólogo se obtenían mejores resultados que al hacer la mezcla con un aloinjerto. En cambio, otros estudios recientes obtienen mejores resultados mezclando un aloinjerto en comparación con el hueso autólogo $100 \%(25,36,37)$. Otro factor importante que se analizó fue el papel que desempeña la altura del hueso residual en el éxito del tratamiento, concluyendo que es necesaria una presencia mínima de hueso vital del 25 al 35\% (en relación con la cantidad total de hueso injertado) para conseguir una buena oseointegración. Sin embargo, en un estudio de Price y cols. (38) no encuentran una relación significativa entre la distancia de la membrana sinusal al suelo del seno maxilar ni en la altura de la cresta ósea residual en el resultado final del injerto. Los hallazgos sugieren un papel pasivo para el material de injerto y señalan al crecimiento de tejido vascular y perivascular como la fuente más lógica de la capacidad osteogénica.

Aunque la elevación del suelo del seno maxilar con fines implantológicos es uno de los procedimientos más predecibles de aumento óseo, muestra un mayor porcentaje de fracasos comparada con implantes colocados en hueso nativo $(39,40)$. Estos resultados pueden deberse a complicaciones intraoperatorias (perforación de la membrana sinusal, fractura del reborde alveolar residual, obstrucción del ostium sinusal, hemorragia y lesión de los dientes adyacentes), complicaciones postoperatorias tempranas (hemorragia, dehiscencia de la herida, infección aguda, exposición de la membrana, infección o pérdida del injerto y fracaso del implante) y postoperatorias tardías (pérdida del injerto o del implante, migración del implante, fístula bucosinusal, dolor y sinusitis crónicas) (17).

La perforación accidental de la membrana de Schneider es una de las complicaciones más frecuentes durante su manipulación, registrándose una incidencia del 10\% al $60 \%$. Su aparición no es una indicación absoluta de abandono del procedimiento, salvo que exista una gran 
destrucción. En el resto de situaciones puede repararse mediante la colocación de puntos de sutura, malla de celulosa oxidada, cola de fibrina, mediante el replegamiento de la propia membrana (en pequeñas perforaciones) o con el uso de membranas de colágeno reabsorbibles (en perforaciones más amplias). En el estudio de Oh y Kraut (41), en un total de 175 senos maxilares elevados, se registraron un $34 \%$ de perforaciones, 4 infecciones $(2,2 \%), 3$ de las cuales ocurrieron en membranas previamente dañadas y 5 implantes fracasados, 4 de ellos en casos con perforación sinusal. El porcentaje de éxito final fue del $99 \%$ en los senos maxilares intactos y de un $97 \%$ en los senos perforados.

Los septos sinusales son unas estructuras que deben conocerse previamente al acto quirúrgico ya que pueden impedir el acceso al antro desde la ventana lateral, además de que pueden aumentar el riesgo de perforación de la membrana sinusal debido a la fuerte unión de ésta con la pared del septo. Para su identificación es necesario un estudio mediante una tomografía computadorizada (TC) ya que la radiografía panorámica puede dar muchas imágenes con falsos positivos y negativos (42). Se ha descrito una incidencia de septos sinusales del $37 \%$, siendo bilaterales el $31,1 \%$ de éstos. Es más frecuente encontrar un solo septo y en una situación medial, que en localizaciones posterior y anterior (43).

Existen otros signos que inducen la sospecha de patología sinusal cuando se observa una TC. Pueden aparecer áreas localizadas o difusas de adelgazamiento mucoso, radiopacidad bien definidas que emergen del suelo del seno maxilar (atribuyéndose a quistes de retención o pseudoquistes) o una ocupación completa del seno maxilar consecuencia de una sinusitis o de mucoceles. En un estudio de Maestre-Ferrín y cols. (44) sobre 30 pacientes la alteración más prevalente fue la de adelgazamiento de la membrana sinusal.

Los quistes sinusales tienen una prevalencia del $21 \%$ y existe controversia en cuanto a si su presencia supone una contraindicación absoluta para efectuar una elevación de seno maxilar. En el caso en que se opte por su extirpación previa deben dejarse pasar un mínimo de 6 meses de cicatrización antes de proceder a la elevación sinusal. En un caso clínico de Acocella y cols. (45) realizan una elevación de seno maxilar en presencia de un quiste sinusal sin que aparecieran complicaciones postoperatorias, por lo que estos autores concluyen que estos quistes no deben representar una contraindicación absoluta.
Otras complicaciones están originadas por variaciones anatómicas o patologías sinusales previas que pasan inadvertidas al clínico, como puede ser la estenosis del ostium, cuya función de drenaje del seno maxilar a la cavidad nasal es fundamental para una buena función sinusal. Ésta puede encontrarse hasta en el $24 \%$ de los pacientes y puede ser de ayuda la consulta preoperatoria al otorrinolaringólogo (2). Es por este motivo que un estudio de Torretta y cols. (46) recomiendan una exploración exhaustiva nasal, del oído y la garganta, con la intención de descubrir factores de riesgos generales y específicos, acompañada de una endoscopia nasal con fibra óptica y una TC que se extienda hasta el techo etmoidal y permita visualizar el complejo osteomeatal.

Es especialmente importante el conocimiento de la anatomía vascular de la zona, sobretodo de la pared anterolateral del seno maxilar, para evitar hemorragias que dificulten la visualización de la membrana de Schneider e interfieran en la colocación del injerto. En esta pared se localiza una anastomosis intraósea de una rama de la arteria alveolar superior posterior con la arteria infraorbitaria. El diámetro de este vaso suele medir < l mm y puede tener 3 recorridos: dentro de la cortical vestibular, entre la membrana y el hueso o debajo del periostio de la pared lateral del seno. La mayoría de veces se encuentra en posición intraósea en los extremos y parcialmente intraósea (en contacto con la membrana de Schneider) en su zona central (del $2^{\circ}$ premolar al $2^{\circ}$ molar). En relación a su posición a nivel vertical, hay que extremar la precaución de no lesionarla cuando la altura residual de la cresta alveolar es menor de $3 \mathrm{~mm}$ (47).

\section{REGENERACIÓN ÓSEA GUIADA}

El éxito a largo plazo de los implantes oseointegrados requiere de un suficiente volumen de hueso remanente que rodee al implante de una forma estable en el tiempo. Sin embargo, con frecuencia la cantidad de hueso remanente es insuficiente debido a la reabsorción que se produce tras la exodoncia, por un traumatismo o por la pérdida de dientes por una infección, entre otras causas, por lo que en ocasiones debe recurrirse a técnicas de regeneración ósea guiada (ROG) para su recuperación, de forma previa o simultánea a la colocación de los implantes.

Cuando se extrae un diente, existe una pérdida tridimensional de hueso alveolar inevitable. La pérdida ósea horizontal ocurre de forma más rápida y extensa 
que la pérdida ósea vertical. Ésta última se estima en un $40 \%$, mientras que la horizontal es de un $60 \%$ a los 6 meses postextracción. La reconstrucción del hueso atrófico requiere técnicas de aumento como la ROG, la expansión de la cresta alveolar, la distracción osteogénica o la utilización de injertos óseos en bloque $(48,49)$.

La ROG consiste en promover la regeneración del hueso mediante la utilización de una membrana como barrera y/o un injerto que impida el colapso de los tejidos blandos y permita la osteopromoción. Las técnicas de ROG que utilizan membranas se basan en tres principios fundamentales: exclusión celular para evitar la invasión de los tejidos epitelial y conectivo en el defecto óseo, estabilidad mecánica para proteger y permitir el proceso de cicatrización y el mantenimiento de un espacio donde puedan migrar las células procedentes del hueso circundante (50).

Comercialmente existen diferentes tipos de membranas que utilizan materiales no reabsorbibles y reabsorbibles. Dentro de las no reabsorbibles se encuentran las de politetrafluroetileno (e-PTFE), politetrafluoroetileno expandido reforzado con titanio (Ti-e-PTFE) y politetrafluoroetileno de alta densidad (d-PTFE). Las membranas de e-PTFE y Ti-e-PTFE (reforzadas de titanio) han sido empleadas en numerosos estudios que confirman su excelente biocompatibilidad y conducen a una regeneración ósea significativa después de un periodo de cicatrización de 3 a 6 meses, pero tienen algunas desventajas, como la necesidad de una segunda intervención quirúrgica para retirarla o la dehiscencia frecuente de la herida debido a su rigidez y su consecuente colonización bacteriana. Como alternativa se pueden utilizar membranas de d-PTFE (alta densidad) que debido a su baja porosidad $(0,2 \mu \mathrm{m})$ resisten la colonización bacteriana y son más fáciles de retirar (50).

Las membranas reabsorbibles se pueden dividir en sintéticas (ácido poliláctico, ácido poliglicólico y sus copolímeros) y naturales (colágeno, pericardio y polímeros naturales), todas ellas tienen la ventaja de no precisar una segunda cirugía, pero tienen algunas desventajas, como la escasez de propiedades mecánicas y capacidad de mantenimiento del espacio, rápida reabsorción y posibilidad de infección durante su degradación. Las membranas de colágeno tienen una alta biodegradabilidad y adhesión celular. Para solucionar este problema se está investigando la posibilidad de incluir compuestos como fosfato cálcico osteoconductivo y polímeros biodegradables, o mo- dificar los polímeros sintéticos para adherir proteínas bioactivas o biomoléculas. La introducción de moléculas específicas permitirían la adhesión celular en la superficie de la membrana favoreciendo una respuesta específica del tejido, y la liberación o la incorporación de sustancias antimicrobianas y factores de crecimiento estimularían la regeneración ósea. El tiempo de reabsorción de las membranas reabsorbibles oscila entre 4 semanas y 12 meses (50).

La degradación de las membranas de colágeno se inicia poco tiempo después de su colocación. Para intentar alargar el tiempo de reabsorción se está utilizando colágeno "cross-linked" (entrecruzado). El número de "cross-link" es proporcional a la rigidez de la membrana y al tiempo de su degradación enzimática, pero la difusión de nutrientes para la proliferación y diferenciación celular no se ve afectada con el uso de estas membranas y parece ser que favorecen la regeneración ósea debido al mantenimiento de su integridad durante más tiempo comparadas con las membranas de colágeno no "cross-linked". Sin embargo, se asocian a una mayor incidencia de dehiscencia de tejidos blandos (51).

Como alternativa a las membranas se propone la opción de utilizar gel de polietileno glicol (PEG) como sistema de barrera y adhesión. Un ensayo clínico de Schwarz y cols. (52) mostró un mayor porcentaje de hueso en contacto con los implantes en el grupo donde se utilizó PEG comparado con el grupo donde se utilizaron membranas de colágeno.

Como ya se ha indicado, los injertos para regenerar hueso pueden clasificarse en cuatro tipos: autoinjerto, aloinjerto, xenoinjerto e injerto aloplástico como ya se ha comentado. A su vez se pueden utilizar en forma de bloque o particulados. Estos últimos son efectivos para corregir pequeños defectos localizados en el reborde alveolar. Las complicaciones derivadas de su uso son pocas y el porcentaje de éxito de la ROG varía del $85,7 \%$ al $100 \%(53)$.

El injerto de hueso autólogo sigue considerándose el estándar de oro por ser osteogénico, osteoconductivo y osteoinductivo, además no provoca respuesta inmune y no tiene riesgo de transmisión de enfermedades infecciosas. Su procedencia puede ser intrabucal o extraoral. Dentro de sus desventajas destacamos la morbilidad del sitio donante, disponibilidad limitada, alteración del perfil del mentón, cicatrices, lesiones nerviosas, recesión gingival y molestias postoperatorias e infección, especialmente cuando se extrae de 
zonas extraorales (cresta ilíaca, calota craneal, fémur, peroné, tibia, etc.) $(49,54-56)$.

La utilización de injertos de mandíbula, de rama ascendente o de mentón, ha reportado excelentes resultados en términos de éxito y supervivencia de los implantes, con menos complicaciones en relación con el sitio donante, aunque cuando se extrae hueso del mentón pueden aparecer leves alteraciones sensoriales en la mucosa bucal y los dientes pero en la mayoría de los casos son temporales (57). La utilización de hueso bovino liofilizado particulado y membranas de colágeno alrededor y encima de un injerto autólogo en bloque puede minimizar la reabsorción del injerto durante el periodo de revascularización, aunque puede incrementar la frecuencia de aparición de complicaciones y añadir dificultad a la técnica (58).

El injerto de hueso autólogo monocortical facilita de forma predecible el aumento horizontal y vertical del reborde alveolar y la reparación de defectos óseos, tiene un periodo de cicatrización más corto que los substitutos de hueso, lo que permite la colocación de implantes a los 4 meses. Además la calidad del injerto a menudo es mejor que la densidad que tiene el hueso del maxilar superior, por lo que mejora la estabilidad del implante y acorta el tiempo de carga (48).

Con unos porcentajes de éxito comparables al injerto autólogo se encuentra el aloinjerto, hueso liofilizado desmineralizado o no procedente de un banco de tejidos. Es principalmente osteoconductor con escasas propiedades osteoinductoras pero ha demostrado ser efectivo para la regeneración ósea con una tasa de supervivencia de los implantes colocados en él que varía entre un $79,3 \%$ y un $95,6 \%$ cuando se utiliza en forma de bloque $(49,59-61)$. Es una buena alternativa al autoinjerto debido a que debe hacerse un menor traumatismo quirúrgico y a su disponibilidad ilimitada, además de que después de la cicatrización muestra un patrón histológico similar al de los injertos de hueso autólogo (62).

Los xenoinjertos, hueso bovino, porcino y equino, también son osteoconductores y son muy utilizados. Son generalmente bien tolerados y tienen una velocidad de reabsorción lenta, lo que permite mantener el volumen del injerto, pero no son osteogénicos lo que da como resultado la obtención de menos hueso vital $(49,56)$. El hueso porcino es biocompatible y altamente osteoconductivo para regenerar alvéolos postextracción (63). También se ha demostrado la efectividad del hueso equino mediante la utilización de láminas flexi- bles obtenidas del hueso femoral para regenerar defectos verticales en la mandíbula y en el maxilar superior (64), así como en forma de bloques en combinación con plasma rico en factores de crecimiento para el aumento horizontal con muy buenos resultados (65).

La utilización de injertos óseos en combinación con membranas reabsorbibles para regenerar defectos alrededor de implantes inmediatos ha mostrado ser más efectiva que la utilización de injertos óseos solos. Según De Angelis y cols. (66) con esta técnica se obtuvo $0,70 \mathrm{~mm}$ más de hueso marginal alrededor del implante además de una mejora en los resultados estéticos.

Varios estudios muestran un alto grado de regeneración y un contacto hueso-implante satisfactorio al cubrir dehiscencias en implantes inmediatos en el sector anterior con hueso bovino liofilizado o hueso autólogo combinados con una membrana de colágeno. Debe tenerse en cuenta que el injerto se reabsorbe un $50 \%$ a los 4 meses y que el biotipo gingival no parece afectar al volumen del injerto. No existen diferencias significativas al comparar hueso bovino liofilizado con hueso autólogo (66-70).

Los injertos aloplásticos como el fosfato beta-tricálcico, la hidroxiapatita y los cristales bioactivos son materiales sintéticos inorgánicos utilizados principalmente para rellenar defectos (49). Se sigue investigando en nuevos materiales substitutos de hueso como el polimetilmetacrilato, poihidroxietilmetacrilato, hidróxido de calcio con polianhídrido, que muestran buenos resultados, pero cabe destacar que estos estudios se han efectuado en animales, siempre en alveolos postextracción de premolares mandibulares que suelen tener un buen grosor de cortical (71).

Algunos ensayos clínicos experimentales indicaban que la utilización de sustancias como el derivado de la matriz del esmalte o la hormona paratiroidea podían tener un efecto estimulante en la formación de hueso, pero se ha demostrado que no es así (72). Sin embargo, parece ser que la inyección local de simvastatina o la aplicación tópica de hormona del crecimiento pueden llegar a inducir osteoformación, pero son necesarios más estudios experimentales que aclaren el posible uso de estas sustancias en la ROG $(73,74)$.

La preservación de los alveolos postextracción es objeto de controversia. Hay autores que demuestran su eficacia al utilizar xenoinjertos, hueso autólogo o alogénico siempre y cuando se protejan con una membrana reabsorbible. Se estima una pérdida media de 
la anchura del alveolo posterior a la exodoncia de aproximadamente un $30 \%(75,76)$. Sin embargo, otros autores demuestran lo contrario, obteniendo mayor cantidad de hueso en alveolos no regenerados en comparación con los regenerados, pero se debe tener en cuenta que no se utilizaron membranas para cubrir estos alveolos (77-79).

La regeneración vertical de la zona posterior de la mandíbula supone un reto terapéutico por lo que se han ensayado diferentes alternativas. La colocación de implantes cortos puede ser una alternativa a la regeneración vertical, siempre que exista una altura de hueso residual de por lo menos 7-8 mm por encima del conducto dentario inferior y de que los tejidos blandos no interfieran en la colocación de la prótesis. Se consigue un tratamiento más rápido, de menor coste y asociado a una menor morbilidad (80-83). La utilización de factores de crecimiento también ha resultado ser eficaz. Misch (84) ensayó la utilización de esponjas de colágeno acelular impregnadas de proteína morfogenética ósea humana recombinada tipo 2 (rhBMP-2) mezclada con partículas de hueso alogénico recubiertas con una malla de titanio en la zona posterior mandibular atrófica. Después de 6 meses la formación ósea fue suficiente para colocar implantes de $4 \mathrm{~mm}$ de diámetro y longitudes comprendidas entre los 8 y los $13 \mathrm{~mm}$.

Otra posibilidad de tratamiento de las reabsorciones severas es la expansión de la cresta alveolar o el "split crest" (corticotomía supracrestal) que se utiliza especialmente para corregir defectos horizontales. Estas técnicas requieren el uso de escoplos y osteótomos para expandir la cresta alveolar longitudinalmente, provocando una fractura en tallo verde de la cortical vestibular. En un estudio de Mazzocco y cols. (85) se probó con éxito un nuevo sistema para expandir crestas atróficas sin la necesidad de utilizar martillo y escoplo que consiste en la utilización de una secuencia de fresas sin corte de diámetro creciente. Otra opción presentada, es la utilización de expansores de diámetro creciente que introducidos en el lecho implantario, consiguen comprimir el hueso esponjoso hacia la cortical, lo que produce una mejora en la densidad del hueso maxilar y una mejor estabilidad primaria de los implantes además de la expansión ósea, se trata en consecuencia de una técnica predecible y menos invasiva $(86,87)$. González-García y cols. (88) han descrito una modificación de esta técnica en la que, además de la corticotomía crestal, se hacen dos osteotomías verticales por distal y mesial a ésta que permiten la expansión con mayor facilidad mediante la introducción de un escoplo fino, produciendo una fractura en tallo ver- de sin llegar a despegar toda la cortical vestibular en bloque y conservando así su irrigación con más garantías. Tras esta maniobra se efectúa la inserción progresiva de los osteótomos finos entre las corticales para obtener el ensanchamiento deseado y poder colocar los implantes. El espacio se rellena con hueso autólogo mezclado con hueso bovino liofilizado y se cubre con una membrana de colágeno reabsorbible. La ventaja de esta técnica respecto al "split crest" convencional es que facilita una mayor expansión de las corticales y disminuye el riesgo de necrosis de la cortical vestibular.

Demetriades y cols. (86) describen otra modificación de la técnica en dos pasos cuando la anchura de la cresta alveolar es menor de $3 \mathrm{~mm}$ o cuando las corticales son muy densas. Consiste en practicar una osteotomía completa efectuando una corticotomía crestal completa unida a dos cortes verticales por distal y mesial y un corte horizontal más apical sin despegar el fragmento de hueso. Se sutura el colgajo y se deja cicatrizar durante 3-4 semanas para que se forme el callo óseo. En una segunda intervención quirúrgica se practica la expansión de la cresta con osteótomos de diámetro creciente en la zona crestal del callo óseo, y a continuación se colocan los implantes. Esta modificación evita fracturas desfavorables en la cortical vestibular según los autores.

Para grandes defectos óseos se están investigando nuevas técnicas que permitan conseguir un injerto hecho a medida. Mediante la utilización de la TC se prepara un modelo con masilla del hueso a reconstruir en tamaño real. Posteriormente se aplica una cera de parafina radioopaca en el defecto y se modela hasta conseguir la forma deseada teniendo en cuenta los tejidos blandos. Este modelo se vuelve a escanear mediante TC, lo que proporcionará la forma exacta de la estructura para ser reproducida con hueso artificial. Esta nueva técnica es ligeramente más compleja que los métodos convencionales pero consigue un ajuste casi perfecto y unos resultados estéticos óptimos (89).

Para el tratamiento de las anomalías o dismorfias maxilomandibulares se han utilizado clásicamente las osteotomías (cirugía ortognática). Existen varios estudios como los de De Santis y cols., Jensen y cols., Bormann y cols. y Scarano y cols. (90-93), que utilizan estas técnicas combinadas con ROG para el tratamiento de grandes atrofias, mediante la interposición de hueso autólogo o xenoinjertos cubiertos con membranas en la línea de la osteotomía (técnica de sandwich). Todos estos autores demuestran que es una técnica predecible que 
permite la colocación de implantes a los 4 meses y con un porcentaje de éxito que oscila entre el 95-100\%.

Otra alternativa es la utilización de distractores osteogénicos unidireccionales o bidireccionales asociados a las osteotomías. Esta técnica permite conseguir un aumento importante de volumen en poco tiempo, consiguiendo en un mes el volumen deseado y en tres meses la densidad de éste ya se asemeja a la del hueso circundante. Pero esta técnica no está exenta de complicaciones como la mala dirección del fragmento del hueso distraído, y la incomodidad del paciente debido al dispositivo distractor (94).

En un estudio de Chiapasco y cols. (95) se ha probado el uso de injertos de peroné incluyendo la arteria y vena peroneales para reconstruir grandes atrofias maxilares en 12 pacientes, para posteriormente proceder a la colocación de 75 implantes. Este tipo de regeneración no garantizó la estabilidad dimensional del hueso periimplantario a pesar de la irrigación inmediata proporcionada por el pedículo vascular. La supervivencia de los implantes fue de un $95,8 \%$ pero un gran número de ellos presentaba una pérdida ósea periimplantaria de 1 a $7 \mathrm{~mm}$ en el maxilar superior y de 1 a $4,5 \mathrm{~mm}$ en la mandíbula.

Para evitar cicatrices en el sector estético HernándezAlfaro y cols. (96) describen una nueva técnica de acceso para regenerar pequeños defectos óseos. Mediante una incisión sulcular se levanta un colgajo de espesor completo sin realizar descargas verticales. Para evitar la tensión del colgajo se efectúan incisiones horizontales en el periostio. Una vez extraído y remodelado el injerto en bloque de la rama ascendente de la mandíbula o del mentón, éste se fija mediante un tornillo colocado en la zona más coronal del injerto o en los casos en que el acceso a través del colgajo no lo permita se coloca transmucoso. En este ensayo se utilizó hueso particulado y membrana de colágeno reabsorbible para cubrir el injerto en algunos casos y posteriormente se procedió a suturar la herida.

Esta nueva incisión en sobre mejora la vascularización del colgajo mucoperióstico y evita las descargas verticales que pueden comprometer la estética en pacientes con sonrisa gingival.

\section{FACTORES DE CRECIMIENTO}

Entendemos por factor de crecimiento todas las sustancias con capacidad de promover y aumentar la neo- formación de un tejido. Desde hace unos años, son múltiples las investigaciones que han incorporado, con excelentes resultados, algunos de estos factores de crecimiento en las técnicas de regeneración ósea con el fin de mejorar sus resultados.

Entre los factores de crecimiento que se han utilizado en la clínica destacan: las proteínas morfogenéticas (BMPs), el factor de crecimiento y diferenciación recombinante humano 5 (rhGDF-5), el factor BB recombinante derivado de las plaquetas (rhPDGF-BB), el plasma rico en factores de crecimiento (PRGF) o el plasma rico en plaquetas (PRP) y la hormona del crecimiento $(\mathrm{GH})$.

\section{Hormona del crecimiento}

La hormona del crecimiento (Growth Hormone-GH) es capaz de aumentar el crecimiento óseo de una manera dosis-dependiente por la estimulación directa de los condrocitos epifisarios. Gracias a esta acción se logra estimular la proliferación y diferenciación de células condroprogenitoras. Estudios recientes has demostrado que el uso de la GH mejora la respuesta ósea alrededor de los implantes dentales. En un estudio en perros evaluaron histológicamente el efecto de usar la GH alrededor de implantes dentales colocados inmediatamente en alveolos tras la exodoncia. En el lado control, se colocaron implantes inmediatos y en el lado estudio, se colocaron inmediatamente los implantes dentales asociados a la GH en polvo. Se sacrificaron los animales a las 2,6 y 12 semanas del postoperatorio y se valoraron las muestras. La formación de hueso nuevo fue observada en ambos grupos, pero en el grupo estudio, la densidad del hueso fue mayor y las fibras de colágeno estaban mejor orientadas, concluyendo que el uso de la GH mejoraba la formación de hueso alrededor de los implantes (97). Sin embargo, en otro estudio en perros, la aplicación tópica de 4 UI de GH como un agente biomimético en el momento de la colocación del implante no tuvo efectos significativos sobre el contacto entre el hueso y el implante a las 5 y 8 semanas, a pesar de que la neoformación ósea entre las roscas del implante se incrementó significativamente (74).

\section{Proteínas morfogenéticas}

Muchos estudios han examinado las propiedades osteoinductivas de las BMPs y su capacidad para ayudar a la regeneración ósea en la cavidad bucal. Entre los 
distintos miembros de la familia de las BMPs, la BMP-2 ha recibido una atención especial. En la cavidad bucal la BMP recombinante humana-2 (rhBMP-2) ha demostrado que estimula la regeneración de los rebordes alveolares, los tejidos periodontales y el hueso alrededor de los implantes de titanio $(98,99)$. Rotenberg y cols. (100) reportaron un caso en el que trataron un defecto circunferencial alrededor de un implante dental utilizando rhBMP-2 en combinación con hueso alogénico no desmineralizado (FDBA). Los controles se realizaron a las 20,28 , y 80 semanas. A las 20 semanas la evaluación mediante radiografía periapical mostró que la mayor parte del defecto se había rellenado. La exploración clínica, reveló una profundidad de sondaje de $2 \mathrm{~mm}$ y ausencia de sangrado. A las 28 semanas, se coloco una corona atornillada al implante. El examen radiográfico a las 80 semanas mostró alguna pérdida de hueso alrededor del implante en comparación con los resultados radiográficos observados a las 28 semanas. Sin embargo el examen clínico constató la ausencia de inflamación (ausencia de sangrado al sondaje) y una profundidad de sondaje de $4 \mathrm{~mm}$. Los resultados clínicos y radiográficos en este caso sugieren que la rhBMP-2 puede ser utilizada para tratar defectos periimplantarios. En un estudio en perros Wang y cols. (101) concluyeron que la rhBMP-2 y el factor de crecimiento fibroblástico tenían una acción sinérgica en el tratamiento de defectos óseos. La combinación de estos factores de crecimiento lograban una formación de hueso mayor comparado con otro tipo de combinaciones.

\section{Factor BB recombinante derivado de las plaquetas}

Jayakumar y cols. (102), efectuaron un estudio para evaluar la seguridad y eficacia del factor de crecimiento recombinante humano derivado de plaquetas (rhPDGF-BB) y el B-fosfato tricálcico (TCP- B) en pacientes con defectos periodontales. Se trata de un ensayo clínico prospectivo, a doble ciego, paralelo, controlado, aleatorizado y multicéntrico, en 54 pacientes con defectos óseos periodontales que fueron asignados aleatoriamente al grupo rhPDGF-BB $+\beta-$ TCP (grupo estudio) o al $\beta$-TCP solo (grupo control). Entre los resultados más destacados se observo que el grado de crecimiento lineal del hueso y el porcentaje de relleno óseo en el sexto mes respecto al valor basal fue mayor de forma estadísticamente significativa en el grupo de rhPDGF-BB $+\beta-\mathrm{TCP}$, en comparación con el grupo de $B$-TCP solo. No se observaron efectos secundarios graves en ninguno de los dos grupos, aun- que se registraron complicaciones menores como fiebre, dolor y edema en ambos grupos.

En otro estudio se prepararon tres defectos circunferenciales de tamaño crítico en el hueso ilíaco de seis ovejas. Se colocaron tres implantes dentales en el centro de cada defecto y el espacio circunferencial de 3,25 $\mathrm{mm}$ se rellenó con:

a) Coágulo de sangre.

b) $B-T C P$.

c) $\operatorname{rhPDGF}-\mathrm{BB}(0,3 \mathrm{mg} / \mathrm{ml})$ con $\beta-\mathrm{TCP}$.

Todos los defectos en cada grupo fueron cubiertos con una membrana reabsorbible. Las ovejas se sacrificaron a las 2 y 4 semanas y efectuaron los análisis histológicos e histomorfométricos para determinar el porcentaje de formación de hueso nuevo mineralizado y la presencia de partículas residuales de $\beta$ - TCP en los defectos. Los defectos rellenados con rhPDGF-BB $+B$ -TCP mostraron la mayor tasa de formación de hueso después de 2 y 4 semanas, y una reabsorción limitada de las partículas $B$-TCP a las 4 semanas. Los defectos rellenados solo con $B$-TCP mostraron la menor formación ósea después de 2 y 4 semanas, y una degradación más rápida de las partículas de $B$-TCP a las 4 semanas en comparación con defectos en los que se utilizó rhPDGF-BB + B-TCP. El porcentaje de hueso mineralizado nuevo era comparable en los defectos con el coagulo y con el B-TCP después de 4 semanas, pero se produjo el colapso de los defectos ocupados solo por el coagulo sanguíneo (103).

\section{Plasma rico en factores de crecimiento o el plasma rico en plaquetas}

Las investigaciones en humanos, animales y en modelos "in vitro" han demostrado que la aplicación de factores de crecimiento tales como el plasma rico en plaquetas (PRP) o el plasma rico en factores de crecimiento (PRGF), ya sea directamente al hueso autólogo, aloinjertos, xenoinjertos, o aloplásticos o dentro de los defectos óseos, puede conducir a tasas de curación más rápida y a una posible mayor formación de hueso. Birang y cols. (104) efectuaron un estudio en animales donde investigaron el efecto del PRGF en la curación del hueso periimplantario, previo a la colocación de los implantes y aplicado sobre su superficie. Los implantes fueron retirados a las 12 semanas. Los implantes tratados con PRGF mostraron más contacto hueso-implante en comparación con el grupo control (sin PRGF). Además, se registraron valores más altos de espesor de hueso trabecular y de madurez 
ósea en las zonas tratadas con PRGF que en el grupo control.

\section{CIRUGÍA GUIADA}

Para aumentar la precisión de la colocación de los implantes dentales y minimizar los riesgos de dañar las estructuras anatómicas se han introduciendo nuevas tecnologías tales como la planificación implantológica basada en datos tomográficos tridimensionales como la TC y/o tomografía computadorizada de haz cónico (TCHC) que permiten la planificación de una cirugía guiada por la imagen, de este modo se puede llegar a diagnósticos, planificación y tratamientos más precisos y predecibles (105).

La cirugía sin colgajo ("flapless") está especialmente indicada en pacientes que presentan una capacidad regenerativa/cicatricial disminuida tales como los irradiados en el área de cabeza y cuello ya que con este tipo de técnica se disminuye el traumatismo quirúrgico. Por esta misma razón se puede aplicar también en los pacientes con discrasias sanguíneas $(105,106)$.

Hoy en día hay disponibles tres tipos de guías quirúrgicas generadas por ordenador, las dentosoportadas, mucosoportadas y las oseosoportadas. Estas últimas, según la literatura, presentan la mayor tasa de desviación respecto a la planificación, siendo las más precisas las dentosoportadas. Los clínicos que utilicen esta tecnología deben seguir una buena formación continuada. El odontólogo debe tener amplios conocimientos para hacer un correcto análisis de la TC y/o la TCHC, un gran dominio del manejo del "software" y saber efectuar una correcta selección de los pacientes y ejecutar un correcto plan de tratamiento (106).

La cirugía implantológica guiada por la imagen facilita la colocación del implante en una posición ideal previamente determinada por la prótesis, o sea, que la posición final del diente se diseña antes de la colocación del implante.

Como cualquier técnica quirúrgica, esta técnica no está exenta de limitaciones, tales como, la colocación inmediata del implante tras la extracción del diente, la redistribución de los tejidos blandos así como la regularización de la cresta alveolar para crear una buena plataforma (107).

Aunque se puede ser algo escéptico respecto a este tipo de tecnología, presenta una gran precisión en la información de los contornos de los tejidos blandos cuando se compara con las guías quirúrgicas convencionales fabricadas por un laboratorio protésico (108).

Diversos estudios confirman la alta predictibilidad del "software" de planificación tridimensional en relación a la fiabilidad entre lo que se planea y el resultado quirúrgico. Otros estudios demuestran que en este tipo de técnica se produce un acúmulo de pequeños errores (durante el escaneo de la TC y/o la TCHC, la fabricación de la férula quirúrgica y en la fijación de ésta) que resultan en una falta de precisión de esta tecnología $(107,109,110)$. Casap y cols. (111) en un estudio preliminar destacan la viabilidad de la implantología guiada por la imagen para planear y ejecutar una rehabilitación con 3 implantes con un patrón geométrico que coincida con una férula metálica prefabricada y así lograr una restauración protésica inmediata concluyendo que es una técnica con buenos resultados, aunque se necesitan más estudios que confirmen estos datos preliminares.

La carga inmediata de los implantes colocados con este tipo de cirugía guiada por la imagen presenta diversos problemas en el momento de instalar la prótesis ya fabricada, tales como, la falta de pasividad y ajuste de la prótesis, lo que provoca un exceso o una carga incorrecta sobre los implantes, así como la falta de precisión en el momento del rebase de la prótesis en boca (110). Benech y cols. (112) presentan un caso clínico en lo cual colocaron, mediante cirugía guiada, 10 implantes simultáneamente a una osteotomía de Le Fort I que se cargaron de forma inmediata. A los 12 meses, los implantes presentaban una buena oseointegración y una función protésica y estética correctas.

\section{IMPLANTES CIGOIMÁTICOS}

Para el tratamiento de las grandes atrofias del maxilar superior, han sido propuestas numerosas técnicas como la utilización de implantes angulados en la región parasinusal, implantes anclados en la apófisis pterigoides, elevaciones del seno maxilar, implantes cortos o implantes cigomáticos.

En pacientes sometidos a cirugía resectiva oncológi$\mathrm{ca}$, que han sufrido traumatismos graves, con defectos congénitos, con fracaso de injertos autólogos o pacientes que rechazan el tratamiento mediante la utilización de injertos autólogos, la utilización de implantes cigomáticos representa una alternativa en la rehabilitación bucal y del tercio medio facial y actualmente son tam- 
bién utilizados en rehabilitaciones de pacientes con atrofias severas del maxilar superior (113).

En la literatura se describe una tasa de éxito en las restauraciones sobre implantes cigomáticos que oscila entre el $97 \%$ y el $100 \%$ (114-116).

La técnica clásica consiste principalmente en la colocación de los implantes pasando a través del seno maxilar hasta alcanzar el arco cigomático. Actualmente existen estudios que describen las ventajas de diferentes variaciones respecto a la técnica original (113).

La técnica de Stella y Warner ("sinus slot technique") fue la primera descrita que intentaba mejorar quirúrgicamente la técnica clásica (113). Esta técnica consiste en la realización de una pequeña ventana en la pared lateral del seno maxilar que sirve de guía y permite la visión directa de la base del hueso cigomático, ayuda a controlar la posición del implante y elimina la necesidad de efectuar la tradicional ventana de acceso al seno maxilar. Se aumenta el área de contacto entre el hueso maxilar y el implante, debido a su posición más lateralizada, y se reduce la superficie de implante expuesto. La disección requerida es inferior respecto al protocolo original y la mucosa palatina sólo se levanta para exponer la cresta alveolar, minimizando de este modo la morbilidad $(113,117)$. Esta técnica se aplica en los casos en que se busca una emergencia más crestal, especialmente en pacientes que conservan el proceso alveolar, ya que permite la colocación del implante con un ángulo más vertical, situando la cabeza del implante hacia vestibular a nivel del primer molar y mejorando de esta forma el resultado de la rehabilitación protésica (113).

Esta técnica fue posteriormente criticada por algunos autores, argumentando que esta ranura-guía no permitía la visualización correcta del hueso cigomático, hecho importantísimo para evitar posibles complicaciones (113).

La "técnica exteriorizada" fue la siguiente técnica descrita para intentar mejorar la técnica clásica. Este abordaje elimina la necesidad de practicar una antrostomía o una ranura-guía, mejora la visualización del campo quirúrgico, y permite reducir la posición palatinizada de la emergencia del implante, mejorando la estética y la biomecánica de la prótesis (113). En un estudio retrospectivo, Migliorança y cols. (114) obtuvieron un tasa de éxito del $98,7 \%$ en implantes cigomáticos colocados con la técnica exteriorizada, demostrando que es una técnica predecible y con unas tasas de éxito similares a las técnicas descritas anteriormente.
La colocación de implantes cigomáticos con un trayecto intrasinusal puede no ser posible en pacientes con una concavidad muy marcada de la pared vestibular del seno maxilar. En estos casos, la técnica exteriorizada es una buena opción. Los implantes son colocados externamente al hueso maxilar superior y anclados únicamente en el hueso cigomático, haciendo de esta técnica una opción para todos los tipos de maxilares superiores con atrofias severas. Con este abordaje, la mayor parte del implante se encuentra fuera del hueso y cubierto por tejido blando. La técnica exteriorizada presenta menos pasos quirúrgicos respecto a las técnicas clásicas y la "sinus slot technique", es menos invasiva, reduce el tiempo quirúrgico y permite disminuir el "cantilever" de la prótesis ya que la emergencia del implante esta a nivel del primer molar. Esta técnica permite también aumentar la longitud de la perforación del hueso cigomático, ampliando la superficie de contacto entre hueso-implante, promoviendo así una mayor estabilidad mecánica inicial $(117,118)$.

Se ha descrito que gran parte de las complicaciones asociadas a esta "técnica exteriorizada" están relacionadas con el hecho de dejar una considerable porción del implante en contacto con los tejidos blandos que pueden inducir la aparición de dehiscencias, irritación o inflamación de estos tejidos (114).

También se ha propuesto en este campo la utilización de férulas quirúrgicas para planificar una cirugía guiada sin colgajo con implantes cigomáticos. Sin embargo, es recomendable tener una buena visión directa del hueso cigomático, para evitar la colocación de los implantes cerca de la órbita o incluso de su perforación, combinando la utilización de férulas quirúrgicas con la "sinus slot technique". Además, la utilización de férulas quirúrgicas obtenidas por estereolitografía debe ser reevaluada debido a la presencia de grandes desviaciones del trayecto (113).

Para disminuir este efecto negativo, Schiroli y cols. (119) proponen otra modificación a la cirugía guiada, en un estudio con 4 pacientes y un total de 26 implantes (17 en la premaxila, 7 implantes cigomáticos y 1 pterigoideo). Estos autores optaron por las dos fases quirúrgicas: en la primera se colocaron los implantes más anteriores y en la segunda efectuaron una férula quirúrgica estabilizada por estos implantes, y colocaron los implantes cigomáticos guiados con férula y sin colgajo. A los 39 meses estos implantes presentaron una tasa de éxito del $100 \%$.

Chow y cols. (120) recomiendan una combinación de ambas opciones que es la utilización de férulas quirúr- 
gicas basadas en la TC asociadas a la elevación de la membrana sinusal, evitando así su perforación y minimizando los riesgos de producir una sinusitis maxilar.

En contraposición con el abordaje mediante férulas quirúrgicas, se propone la navegación quirúrgica ayudada por ordenador porque ofrece una visualización intraoperatoria constante de la punta de la fresa. Esta técnica permite al cirujano fresar con precisión, controlando la dirección del implante y comprobando la fidelidad de la férula quirúrgica respecto a las estructuras anatómicas (113). Chen y cols. (121) demostraron la precisión de esta técnica en un estudio preliminar, observando una distancia media y desviaciones angulares de 0,58 $\pm 0,18$ mm y $1,12 \pm 0,39^{\circ}$, respectivamente. Aunque la técnica con navegación quirúrgica ayudada por ordenador permite mejorar la precisión del fresado, es un procedimiento caro, prolonga la intervención quirúrgica y está limitada a los centros que tienen el equipamiento necesario para este tipo de intervenciones quirúrgicas (113).

En resumen, la decisión respecto a la elección de una técnica sobre la otra debe tener en cuenta la concavidad formada por el reborde alveolar, el seno maxilar y la región del hueso cigomático que recibe el implante. Cuando el maxilar superior está muy reabsorbido, esta concavidad es pequeña por lo que podría ser emplearse la técnica clásica. Cuando la reabsorción genera una gran concavidad, debe utilizarse la técnica exteriorizada, que puede ser considerada como uno de los mejores abordajes, ya que presenta menos pasos quirúrgicos, es menos invasiva y reduce el tiempo de la intervención quirúrgica (113).

Respecto al grado de satisfacción de los pacientes rehabilitados con prótesis sobre implantes cigomáticos, Sartori y cols. (116) observaron, en un estudio con 16 pacientes, que el $100 \%$ estaban satisfechos con su tratamiento, aunque el $50 \%$ presentaron algún problema relacionado con la prótesis (aflojamiento o rotura del tornillo protésico, aflojamiento de los pilares, desgaste acentuado de los dientes o precisar de rebases por motivos estéticos y/o fonéticos).

Bedrossian y cols. (115) en un estudio prospectivo con 7 años de seguimiento de 74 implantes cigomáticos y 98 implantes colocados en el sector anterior, observaron solo 2 fracasos. Como complicaciones, reportan la existencia de alteraciones neurosensoriales reversibles en 4 pacientes, 3 casos de sinusitis refractaria al tratamiento antibiótico y dificultades en el habla en algunos pacientes por la emergencia palatinizada de los implantes cigomáticos.
De este modo, podemos concluir, que la utilización de implantes cigomáticos, aunque no está libre de complicaciones, supone una opción de tratamiento adecuada en pacientes con reabsorciones severas del maxilar superior.

\section{BIBLIOGRAFÍA}

1. Soltan M, Smiler D, Ghostine M, Prasad HS, Rohrer MD. The crestal approach: Antral membrane elevation via a post graft. Implant Dent 201 1;20:53-60.

2. Almaghrabi BA, Hatton MN, Andreana S, Hoeplinger MA. Treatment of severe sinus infection after sinus lift procedure: A case report. Implant Dent 201 1;20:430-3.

3. Uckan S, Tamer Y, Deniz K. Survival rates of implants inserted in the maxillary sinus area by internal or external approach. Implant Dent 201 1;20:476-9.

4. Baldi D, Menini M, Pera F, Ravera G, Pera P. Sinus floor elevation using osteotomes or piezoelectric surgery. Int J Oral Maxillofac Surg 201 1;40:497-503.

5. Sivolella S, Bressan E, Gnocco E, Berengo M, Favero GA. Maxillary sinus augmentation with bovine bone and simultaneous dental implant placement in conditions of severe alveolar atrophy: A retrospective analysis of a consecutively treated case series. Quintessence Int 2011;42:851-62.

6. Kim YK, Kim SG, Park JY, Yi YJ, Bae JH. Comparison of clinical outcomes of sinus bone graft with simultaneous implant placement: 4-month and 6-month final prosthetic loading. Oral Surg Oral Med Oral Pathol Oral Radiol Endod 2011;111:164-9.

7. Bernardello F, Righi D, Cosci F, Bozzoli P, Soardi Carlo $M$, Spinato S. Crestal sinus lift with sequential drills and simultaneous implant placement in sites with $<5 \mathrm{~mm}$ of native bone: A multicenter retrospective study. Implant Dent $2011 ; 20: 439-44$.

8. Kao DW, Dehaven HA,Jr. Controlled hydrostatic sinus elevation: A novel method of elevating the sinus membrane. Implant Dent 2011;20:425-9.

9. Sammartino G, Mariniello M, Scaravilli MS. Benign paroxysmal positional vertigo following closed sinus floor elevation procedure: Mallet osteotomes vs. screwable osteotomes. A triple blind randomized controlled trial. Clin Oral Implants Res 201 1;22:669-72. 
10. Bensaha T. Evaluation of the capability of a new water lift system to reduce the risk of Schneiderian membrane perforation during sinus elevation. Int J Oral Maxillofac Surg 2011;40:815-20.

11. Kfir E, Kfir V, Kaluski E, Mazor Z, Goldstein M. Minimally invasive antral membrane balloon elevation for single-tooth implant placement. Quintessence Int 201 1;42: 645-50.

12. Stelzle F, Benner KU. Evaluation of different methods of indirect sinus floor elevation for elevation heights of 10mm: An experimental ex vivo study. Clin Implant Dent Relat Res 2011;13:124-33.

13. Trombelli L, Franceschetti G, Rizzi A, Minenna P, Minenna L, Farina R. Minimally invasive transcrestal sinus floor elevation with graft biomaterials. A randomized clinical trial. Clin Oral Implants Res 2011 ;23.424-32.

14. Kolerman R, Moses O, Artzi Z, Barnea E, Tal H. Maxillary sinus augmentation by the crestal core elevation technique. J Periodontol 2011;82:41-51.

15. Kolhatkar S, Bhola M, Thompson-Sloan TN. Sinus floor elevation via the maxillary premolar extraction socket with immediate implant placement: A case series. J Periodontol 2011;82:820-8.

16. Taschieri S, Del Fabbro M. Postextraction osteotome sinus floor elevation technique using plasma-rich growth factors. Implant Dent 2011 ;20:418-24.

17. Farre-Pages N, Auge-Castro ML, Alaejos-Algarra F, Mareque-Bueno J, Ferres-Padro E, Hernandez-Alfaro F. A novel trephine design for sinus lift lateral approach. Case report. Med Oral Patol Oral Cir Bucal 201 1;16:79-82.

18. Penarrocha-Diago MA, Penarrocha-Diago M, SanchezRecio C, Penarrocha-Oltra D, Romero-Millan J. Osteotomy in direct sinus lift. A comparative study of the rotary technique and ultrasound. Med Oral Patol Oral Cir Bucal 2011;17:457-71.

19. Hwang JH, Jung BY, Lim CS, Cha IH, Park W. Posterior maxillary segmental osteotomy concomitant with sinus lift using a piezoelectric device. J Oral Maxillofac Surg $2011 ; 69: 2339-44$.

20. Sbordone C, Sbordone L, Toti P, Martuscelli R, Califano $\mathrm{L}$, Guidetti F. Volume changes of grafted autogenous bone in sinus augmentation procedure. J Oral Maxillofac Surg 2011;69:1633-41.
21. Caubet J, Petzold C, Saez-Torres C, Morey M, Iriarte JI, Sanchez J, et al. Sinus graft with safescraper: 5-year results. J Oral Maxillofac Surg 201 1;69:482-90.

22. Artese L, Piattelli A, Di Stefano DA, Piccirilli M, Pagnutti S, D'Alimonte E, et al. Sinus lift with autologous bone alone or in addition to equine bone: An immunohistochemical study in man. Implant Dent 201 1;20:383-8.

23. Sbordone L, Levin L, Guidetti F, Sbordone C, Glikman A, Schwartz-Arad D. Apical and marginal bone alterations around implants in maxillary sinus augmentation grafted with autogenous bone or bovine bone material and simultaneous or delayed dental implant positioning. Clin Oral Implants Res $2011 ; 22: 485-91$.

24. Mardinger O, Chaushu G, Sigalov S, Herzberg R, Shlomi B, Schwartz-Arad D. Factors affecting changes in sinus graft height between and above the placed implants. Oral Surg Oral Med Oral Pathol Oral Radiol Endod 201 1; 111:6-11.

25. Acocella A, Bertolai R, Nissan J, Sacco R. Clinical, histological and histomorphometrical study of maxillary sinus augmentation using cortico-cancellous fresh frozen bone chips. J Craniomaxillofac Surg 2011;39: 192-9.

26. Won YH, Kim SG, Oh JS, Lim SC. Clinical evaluation of demineralized bone allograft for sinus lifts in humans: A clinical and histologic study. Implant Dent 2011;20: 460-4.

27. Lee CY, Prasad HS, Suzuki JB, Stover JD, Rohrer MD. The correlation of bone mineral density and histologic data in the early grafted maxillary sinus: A preliminary report. Implant Dent 201 1;20:202-14.

28. Canullo L, Dellavia C, Heinemann F. Maxillary sinus floor augmentation using a nano-crystalline hydroxyapatite silica gel: Case series and 3-month preliminary histological results. Ann Anat 2011;194:78.

29. Covani U, Orlando B, Giacomelli L, Cornelini R, Barone A. Implant survival after sinus elevation with Straumann ${ }^{\circledR}$ bone ceramic in clinical practice: Ad-interim results of a prospective study at a 15-month follow-up. Clin Oral Implants Res $2011 ; 22: 481-4$.

30 Ahn JJ, Cho SA, Byrne G, Kim JH, Shin HI. New bone formation following sinus membrane elevation without bone grafting: Histologic findings in humans. Int J Oral Maxillofac Implants 201 1;26:83-90. 
31. Lambert F, Leonard A, Drion P, Sourice S, Layrolle P, Rompen E. Influence of space-filling materials in subantral bone augmentation: Blood clot vs. autogenous bone chips vs. bovine hydroxyapatite. Clin Oral Implants Res. 2011;22:538-45.

32. Simonpieri A, Choukroun J, Del Corso M, Sammartino G, Dohan Ehrenfest DM. Simultaneous sinus-lift and implantation using microthreaded implants and leukocyte- and platelet-rich fibrin as sole grafting material: A six-year experience. Implant Dent 201 1;20:212.

33. Stavropoulos A, Becker J, Capsius B, Acil Y, Wagner W, Terheyden $\mathrm{H}$. Histological evaluation of maxillary sinus floor augmentation with recombinant human growth and differentiation factor-5-coated beta-tricalcium phosphate: Results of a multicenter randomized clinical trial. J Clin Periodontol 2011 ;38:966-74.

34. Rickert D, Sauerbier S, Nagursky H, Menne D, Vissink A, Raghoebar GM. Maxillary sinus floor elevation with bovine bone mineral combined with either autogenous bone or autogenous stem cells: A prospective randomized clinical trial. Clin Oral Implants Res 201 1;22: 251-8.

35. Rickert D, Slater JJ, Meijer HJ, Vissink A, Raghoebar GM. Maxillary sinus lift with solely autogenous bone compared to a combination of autogenous bone and growth factors or (solely) bone substitutes. A systematic review. Int J Oral Maxillofac Surg 2011;22:251-8.

36. Soardi CM, Spinato S, Zaffe D, Wang HL. Atrophic maxillary floor augmentation by mineralized human bone allograft in sinuses of different size: An histologic and histomorphometric analysis. Clin Oral Implants Res 2011;22:560-6.

37. Irinakis T. Efficacy of injectable demineralized bone matrix as graft material during sinus elevation surgery with simultaneous implant placement in the posterior maxilla: Clinical evaluation of 49 sinuses.J Oral Maxillofac Surg 2011;69:134-41.

38. Price AM, Nunn M, Oppenheim FG, Van Dyke TE. De novo bone formation after the sinus lift procedure J Periodontol. 2011 ;82:1245-55.

39. Barone A, Orlando B, Tonelli P, Covani U. Survival rate for implants placed in the posterior maxilla with and without sinus augmentation: A comparative cohort study. J Periodontol 201 1;82:219-26.
40. Kahnberg KE, Wallstrom M, Rasmusson L. Local sinus lift for single-tooth implant: Clinical and radiographic follow-up. Clin Implant Dent Relat Res. 2011;13:231-7.

41. Oh E, Kraut RA. Effect of sinus membrane perforation on dental implant integration: A retrospective study on 128 patients. Implant Dent 201 1;20:13-9.

42. Maestre-Ferrin L, Carrillo-Garcia C, Galan-Gil S, Penarrocha-Diago M, Penarrocha-Diago M. Prevalence, location, and size of maxillary sinus septa: Panoramic radiograph versus computed tomography scan. J Oral Maxillofac Surg 2011;69:507-11.

43. Park YB, Jeon HS, Shim JS, Lee KW, Moon HS. Analysis of the anatomy of the maxillary sinus septum using 3-dimensional computed tomography.J Oral Maxillofac Surg $2011 ; 69: 1070-8$

44. Maestre-Ferrin L, Galan-Gil S, Carrillo-Garcia C, Penarrocha-Diago M. Radiographic findings in the maxillary sinus: Comparison of panoramic radiography with computed tomography. Int J Oral Maxillofac Implants $2011 ; 26: 341-6$.

45. Acocella A, Bertolai R, Nissan J, Ellis E,3rd, Sacco R. Maxillary sinus lift using fresh frozen bone chips in presence of sinus cyst: Clinical and histological report. Cell Tissue Bank 2011;13:327-32.

46. Torretta S, Mantovani M, Testori T, Cappadona M, Pignataro L. Importance of ENT assessment in stratifying candidates for sinus floor elevation: A prospective clinical study. Clin Oral Implants Res 201 1;22:324-9

47. Rosano G, Taschieri S, Gaudy JF, Weinstein T, Del Fabbro M. Maxillary sinus vascular anatomy and its relation to sinus lift surgery. Clin Oral Implants Res 2011;22:711-5.

48. Misch CM. Maxillary autogenous bone grafting. Oral Maxillofac Surg Clin North Am. 201 1;23:229-38.

49. Fu JH, Wang HL. Horizontal bone augmentation: The decision tree. Int J Periodontics Restorative Dent 2011;31:429-36.

50. Gentile P, Chiono V, Tonda-Turo C, Ferreira AM, Ciardelli G. Polymeric membranes for guided bone regeneration. Biotechnol J 201 1;6:1187-97.

51. Friedmann A, Gissel K, Soudan M, Kleber BM, Pitaru $\mathrm{S}$, Dietrich T. Randomized controlled trial on lateral augmentation using two collagen membranes: Morpho- 
metric results on mineralized tissue compound. J Clin Periodontol 2011;38:677-85.

52. Schwarz F, Mihatovic I, Golubovic V, Hegewald A, Becker J. Influence of two barrier membranes on staged guided bone regeneration and osseointegration of titanium implants in dogs: Part 1. Augmentation using bone graft substitutes and autogenous bone. Clin Oral Implants Res 2012;23:83-9.

53. Aloy A, Maestre L, Penarrocha D, Penarrocha M. Bone regeneration using particulate grafts: An update. Med Oral Patol Oral Cir Bucal. 201 1;16:210-4.

54. Barone A, Ricci M, Mangano F, Covani U. Morbidity associated with iliac crest harvesting in the treatment of maxillary and mandibular atrophies: A 10-year analysis. J Oral Maxillofac Surg 2011;69:2298-304.

55. Grecchi F, Zollino I, Gallo F, Rubino G, Motroni A, Carinci F. Computer planning and bone density evaluation of jaws reconstructed with bone grafts from living donors. J Craniofac Surg 2011;22:486-9.

56. Kaing L, Grubor D, Chandu A. Assessment of bone grafts placed within an oral and maxillofacial training programme for implant rehabilitation. Aust Dent J 2011 ; 56:406-11.

57. Cordaro L, Torsello F, Miuccio MT, Di Torresanto VM, Eliopoulos D. Mandibular bone harvesting for alveolar reconstruction and implant placement: Subjective and objective cross-sectional evaluation of donor and recipient site up to 4 years. Clin Oral Implants Res. 2011;22:1320-6.

58. Cordaro L, Torsello F, Morcavallo S, di Torresanto VM. Effect of bovine bone and collagen membranes on healing of mandibular bone blocks: A prospective randomized controlled study. Clin Oral Implants Res 2011;22:1145-50.

59. Nissan J, Ghelfan O, Mardinger O, Calderon S, Chaushu G. Efficacy of cancellous block allograft augmentation prior to implant placement in the posterior atrophic mandible. Clin Implant Dent Relat Res 201 1;13:279-85.

60. Nissan J, Gross O, Mardinger O, Ghelfan O, Sacco R, Chaushu G. Post-traumatic implant-supported restoration of the anterior maxillary teeth using cancellous bone block allografts. J Oral Maxillofac Surg 201 1;69:513-8.

61. Nissan J, Mardinger O, Calderon S, Romanos GE, Chaushu G. Cancellous bone block allografts for the augmentation of the anterior atrophic maxilla. Clin Implant Dent Relat Res 2011;13:104-11.

62. Contar CM, Sarot JR, da Costa MB, Bordini J, de Lima AA, Alanis LR, et al. Fresh-frozen bone allografts in maxillary ridge augmentation: Histologic analysis. J Oral Implantol $2011 ; 37: 223-31$.

63. Crespi R, Cappare P, Romanos GE, Mariani E, Benasciutti $\mathrm{E}$, Gherlone E. Corticocancellous porcine bone in the healing of human extraction sockets: Combining histomorphometry with osteoblast gene expression profiles in vivo. Int J Oral Maxillofac Implants 201 1;26: 866-72.

64. Ludovichetti M, Di Stefano DA, Pagnutti S, Vaccari E, Ludovichetti FS, Celletti R. Vertical ridge augmentation using a flexible heterologous cortical bone sheet:Threeyear follow-up. Int J Periodontics Restorative Dent 2011 ; $31: 401-7$.

65. De Angelis N, Scivetti M. Lateral ridge augmentation using an equine flex bone block infused with recombinant human platelet-derived growth factor $\mathrm{BB}$ : A clinical and histologic study. Int J Periodontics Restorative Dent 2011;31:383-8.

66. De Angelis N, Felice P, Pellegrino G, Camurati A, Gambino P, Esposito M. Guided bone regeneration with and without a bone substitute at single post-extractive implants: 1-year post-loading results from a pragmatic multicentre randomised controlled trial. Eur J Oral Implantol $2011 ; 4: 313-25$.

67. De Santis E, Botticelli D, Pantani F, Pereira FP, Beolchini M, Lang NP. Bone regeneration at implants placed into extraction sockets of maxillary incisors in dogs. Clin Oral Implants Res $2011 ; 22: 430-7$.

68. Verdugo F, Simonian K, Frydman A, D'Addona A, Ponton $J$. Long-term block graft stability in thin periodontal biotype patients: A clinical and tomographic study. Int J Oral Maxillofac Implants 201 1;26:325-32.

69. Schneider D, Grunder U, Ender A, Hammerle CH, Jung $\mathrm{RE}$. Volume gain and stability of peri-implant tissue following bone and soft tissue augmentation: l-year results from a prospective cohort study. Clin Oral Implants Res $2011 ; 22: 28-37$.

70. Al-Khaldi N, Sleeman D, Allen F. Stability of dental implants in grafted bone in the anterior maxilla: Longitudinal study. Br J Oral Maxillofac Surg 201 1;49:319-23. 
71. Hasturk H, Kantarci A, Ghattas M, Schmidt M, Giordano RA, Ashman A, et al. The use of light/chemically hardened polymethylmethacrylate, polyhydroxyethylmethacrylate, and calcium hydroxide graft material in combination with polyanhydride around implants in minipigs: Part I: Immediate stability and function. J Periodontol 2011;82:1339-52.

72. Jensen SS, Chen B, Bornstein MM, Bosshardt DD, Buser D. Effect of enamel matrix derivative and parathyroid hormone on bone formation in standardized osseous defects: An experimental study in minipigs. J Periodontol. 2011;82:1197-205.

73. Rutledge J, Schieber MD, Chamberlain JM, Byarlay M, Killeen AC, Giannini PJ, et al. Simvastatin application to augment facial jaw bone in a dog model: Pilot study. J Periodontol 2011;82:597-605.

74. Calvo-Guirado JL, Mate-Sanchez J, Delgado-Ruiz R, Ramirez-Fernandez MP, Cutando-Soriano A, Pena M. Effects of growth hormone on initial bone formation around dental implants: A dog study. Clin Oral Implants Res $2011 ; 22: 587-93$.

75. Engler-Hamm D, Cheung WS, Yen A, Stark PC, Griffin T. Ridge preservation using a composite bone graft and a bioabsorbable membrane with and without primary wound closure: A comparative clinical trial.J Periodontol 2011;82:377-87.

76. Mardas N, D'Aiuto F, Mezzomo L, Arzoumanidi M, Donos N. Radiographic alveolar bone changes following ridge preservation with two different biomaterials. Clin Oral Implants Res 2011;22:416-23.

77. Heberer S, Al-Chawaf B, Jablonski C, Nelson JJ, Lage H, Nelson K. Healing of ungrafted and grafted extraction sockets after 12 weeks: A prospective clinical study. Int J Oral Maxillofac Implants. 201 1;26:385-92.

78. Baldini N, De Sanctis M, Ferrari M. Deproteinized bovine bone in periodontal and implant surgery. Dent Mater 2011;27:61-70.

79. De Coster P, Browaeys H, De Bruyn H. Healing of extraction sockets filled with BoneCeramic ${ }^{\circledR}$ prior to implant placement: Preliminary histological findings. Clin Implant Dent Relat Res 201 1;13:34-45.

80. Esposito M, Cannizarro G, Soardi E, Pellegrino G, Pistilli $R$, Felice P. A 3-year post-loading report of a randomised controlled trial on the rehabilitation of posterior atrophic mandibles: Short implants or longer implants in vertically augmented bone? Eur J Oral Implantol 2011 ; $4: 301-11$.

81. Esposito M,Pellegrino G, Pistilli R, Felice P. Rehabilitation of postrior atrophic edentulous jaws: Prostheses supported by $5 \mathrm{~mm}$ short implants or by longer implants in augmented bone? One-year results from a pilot randomised clinical trial. Eur J Oral Implantol 201 1;4:2130.

82. Felice P, Pistilli R, Marchetti C, Piana L, Checchi V, Nisii $A$, et al. Reconstruction of atrophied anterior mandible with an inlay technique and resorbable miniplates: $A$ case report. Implant Dent 201 1;20:262-6.

83. Raghoebar GM, Meijer HJ, Stellingsma K, Vissink A. Addressing the atrophied mandible: A proposal for a treatment approach involving endosseous implants. Int J Oral Maxillofac Implants 2011;26:607-17.

84. Misch CM. Bone augmentation of the atrophic posterior mandible for dental implants using rhBMP-2 and titanium mesh: Clinical technique and early results. Int J Periodontics Restorative Dent 201 1;31:581-9.

85. Mazzocco F, Nart J, Cheung WS, Griffin TJ. Prospective evaluation of the use of motorized ridge expanders in guided bone regeneration for future implant sites. Int J Periodontics Restorative Dent 201 1;31:547-54.

86. Demetriades N, Park JI, Laskarides C. Alternative bone expansion technique for implant placement in atrophic edentulous maxilla and mandible.J Oral Implantol 201 1; $37: 463-71$

87. Nishioka RS, de Vasconcellos LG, de Melo Nishioka GN. Comparative strain gauge analysis of external and internal hexagon, Morse taper, and influence of straight and offset implant configuration. Implant Dent. 201 1;20:24-32.

88. González-García R, Monje F, Moreno C. Alveolar split osteotomy for the treatment of the severe narrow ridge maxillary atrophy: A modified technique. Int J Oral Maxillofac Surg 201 1;40:57-64.

89. Saijo H, Kanno Y, Mori Y, Suzuki S, Ohkubo K, Chikazu D, et al. A novel method for designing and fabricating custom-made artificial bones. Int J Oral Maxillofac Surg $2011 ; 40: 955-60$.

90. Scarano A, Carinci F, Assenza B, Piattelli M, Murmura G, Piattelli A. Vertical ridge augmentation of atrophic pos- 
terior mandible using an inlay technique with a xenograft without miniscrews and miniplates: Case series. Clin Oral Implants Res 2011;22:1125-30.

91. De Santis D, Trevisiol L, D’Agostino A, Cucchi A, De Gemmis A, Nocini PF. Guided bone regeneration with autogenous block grafts applied to Le Fort I osteotomy for treatment of severely resorbed maxillae: A 4 to 6 year prospective study. Clin Oral Implants Res 2012;23: 60-9.

92. Jensen OT, Ringeman JL, Cottam JR, Casap N. Orthognathic and osteoperiosteal flap augmentation strategies for maxillary dental implant reconstruction. Oral Maxillofac Surg Clin North Am 201 1;23:301-19.

93. Bormann KH, Suarez-Cunqueiro MM, Von See C, Tavassol F, Dissmann JP, Ruecker M, et al. Forty sandwich osteotomies in atrophic mandibles: A retrospective study. J Oral Maxillofac Surg 201 1;69:1562-70.

94. Xie M, Hu M, Liu H, Xiao H. Primary study of the use of an internal, self-activated shape memory alloy distraction device in the dog mandible: Alveolar ridge distraction and implant placement. J Oral Maxillofac Surg 201 1;69: 2033-9.

95. Chiapasco M, Romeo E, Coggiola A, Brusati R. Long-term outcome of dental implants placed in revascularized fibula free flaps used for the reconstruction of maxillomandibular defects due to extreme atrophy. Clin Oral Implants Res $2011 ; 22: 83-91$.

96. Hernandez-Alfaro F, Salvan E, Mareque J, Ferres E. Envelope approach for onlay bone grafting: Preliminary surgical and prosthetic results. Med Oral Patol Oral Cir Bucal 2011;16:45-9.

97. Hossam AM, Elghamrawy SH, Osman SM, Elhak AR. Histological evaluation of the effect of using growth hormone around immediate dental implants in fresh extraction sockets: An experimental study. Implant Dent $2011 ; 20: 47-55$.

98. Spagnoli DB, Marx RE. Dental implants and the use of rhBMP-2. Oral Maxillofac Surg Clin North Am 201 1;23: 347-61.

99. Huh JB, Park CK, Kim SE, Shim KM, Choi KH, Kim SJ, et al. Alveolar ridge augmentation using anodized implants coated with Escherichia coli-derived recombinant human bone morphogenetic protein 2. Oral Surg Oral Med Oral Pathol Oral Radiol Endod 2011;112:42-9.
100. Rotenberg SA, Tatakis DN. Recombinant human bone morphogenetic protein-2 for peri-implant bone regeneration: A case report.J Periodontol 201 1;82:12128.

101. Wang L, Zou D, Zhang S, Zhao J, Pan K, Huang Y. Repair of bone defects around dental implants with bone morphogenetic protein/fibroblast growth factor-loaded porous calcium phosphate cement: A pilot study in a canine model. Clin Oral Implants Res 2011;22:173-81.

102. Jayakumar A, Rajababu P, Rohini S, Butchibabu K, Naveen $A$, Reddy PK, et al. Multi-centre, randomized clinical trial on the efficacy and safety of recombinant human platelet-derived growth factor with beta-tricalcium phosphate in human intra-osseous periodontal defects. J Clin Periodontol 201 1;38:163-72.

103. Choo T, Marino V, Mark Bartold P. Effect of PDGF-BB and beta-tricalcium phosphate (beta-TCP) on bone formation around dental implants: A pilot study in sheep. Clin Oral Implants Res 2013;24:158-66.

104. Birang R, Tavakoli M, Shahabouei M, Torabi A, Dargahi $A$, Soolari A. Investigation of peri-implant bone healing using autologous plasma rich in growth factors in the canine mandible after 12 weeks: A pilot study. Open Dent J 2011;5:168-73.

105. Abboud M, Orentlicher G. An open system approach for surgical guide production. J Oral Maxillofac Surg $2011 ; 69: 519-24$

106. Orentlicher G, Abboud M. Guided surgery for implant therapy. Oral Maxillofac Surg Clin North Am 2011;23: 239-56.

107. Abad-Gallegos M, Gomez-Santos L, Sanchez-Garces MA, Pinera-Penalva M, Freixes-Gil J, Castro-Garcia A, et al. Complications of guided surgery and immediate loading in oral implantology: A report of 12 cases. Med Oral Patol Oral Cir Bucal 201 1;16:220-4.

108. Amorfini L, Storelli S, Romeo E. Rehabilitation of a dentate mandible requiring a full arch rehabilitation. Immediate loading of a fixed complete denture on 8 implants placed with a bone-supported surgical computer-planned guide: A case report. J Oral Implantol $2011 ; 37: 106-13$

109. Vasak C, Watzak G, Gahleitner A, Strbac G, Schemper $\mathrm{M}$, Zechner W. Computed tomography-based evaluation of template (NobelGuide)-guided implant positions: A 
prospective radiological study. Clin Oral Implants Res 2011;22:1157-63.

110. Yamada K, Hoshina H, Arashiyama T, Arasawa M, AraiY, Uoshima $\mathrm{K}$. Immediate implant loading following computer-guided surgery. J Prosthodont Res 2011;55: 262-5.

111. Casap N, Laviv A, Wexler A. Computerized navigation for immediate loading of dental implants with a prefabricated metal frame: A feasibility study. J Oral Maxillofac Surg 2011;69:512-9.

112. Benech A, Mazzanti C, Arcuri F, Giarda M, Brucoli M. Simultaneous Le Fort I osteotomy and computerguided implant placement. J Craniofac Surg 2011;22: 1042-6.

113. Chrcanovic BR, Pedrosa AR, Custodio AL. Zygomatic implants: A critical review of the surgical techniques. J Oral Maxillofac Surg 2012;39:119-23.

114. Migliorança RM, Coppede A, Dias Rezende RC, de Mayo T. Restoration of the edentulous maxilla using extrasinus zygomatic implants combined with anterior conventional implants: A retrospective study. Int J Oral Maxillofac Implants $2011 ; 26: 665-72$.

115. Bedrossian E. Rehabilitation of the edentulous maxilla with the zygoma concept: A 7-year prospective study. Int J Oral Maxillofac Implants 2010;25:1213-21.

116. Sartori EM, Padovan LE, de Mattias Sartori IA, Ribeiro PD, Jr, Gomes de Souza Carvalho AC, Goiato MC. Evaluation of satisfaction of patients rehabilitated with zygomatic fixtures. J Oral Maxillofac Surg 2012;70:314-9.
117. Cordero EB, Benfatti CA, Bianchini MA, Bez LV, Stanley $\mathrm{K}$, de Souza Magini R. The use of zygomatic implants for the rehabilitation of atrophic maxillas with 2 different techniques: Stella and extrasinus. Oral Surg Oral Med Oral Pathol Oral Radiol Endod 2011;112:49-53.

118. Corvello PC, Montagner A, Batista FC, Smidt R, Shinkai RS. Length of the drilling holes of zygomatic implants inserted with the standard technique or a revised method: A comparative study in dry skulls.J Craniomaxillofac Surg $2011 ; 39: 119-23$.

119. Schiroli G, Angiero F, Silvestrini-Biavati A, Benedicenti S. Zygomatic implant placement with flapless computerguided surgery: A proposed clinical protocol. J Oral Maxillofac Surg 201 1;69:2979-89.

120. Chow J,Wat P, Hui E, Lee P, LiW. A new method to eliminate the risk of maxillary sinusitis with zygomatic implants. Int J Oral Maxillofac Implants 2010;25:1233-40.

121. Chen X, Wu Y, Wang C. Application of a surgical navigation system in the rehabilitation of maxillary defects using zygoma implants: Report of one case. Int J Oral Maxillofac Implants 201 1;26:29-34.

\section{CORRESPONDENCIA}

Prof. Dr. Cosme Gay Escoda

Centro Médico Teknon

Vilana, 12

08022 Barcelona

E-mail: cgay@ub.edu

http://www.gayescoda.com 